\title{
The Nursing Process in Psychiatry
}

\author{
IsABel MoYes, Consultant Psychiatrist, Broadgate Hospital, North Humberside
}

A meeting on the nursing process in psychiatry, organized by the Nursing Committee of the College, was held in Liverpool on 19 April 1982 in conjunction with the Spring Quarterly Meeting.

The purpose of the symposium was to bring to the attention of psychiatrists recent ideas and changes in the practice of nursing, so that consultants might participate more fully themselves in the application of the nursing process and that they might initiate junior doctors in the concepts at an early stage in their training. Professor ANNIE Altschul (Department of Nursing Studies, University of Edinburgh) was in the Chair. In her opening remarks, delivered with characteristic enthusiasm and charm, she pointed out that, although much had been written and spoken in nursing circles about 'the nursing process', the important principle to grasp was the concept of measuring the outcome of care. It was salutary for both nurses and doctors to consider what they were doing to and for patients and whether the results achieved were satisfactory in the broadest sense. In psychiatry one was dealing with the whole individual to a greater degree than in other branches of medicine, so that measurement of outcome could be correspondingly more difficult.

This theme was taken up by the first speaker, MR C. $L$. BAIley (East Surrey District School of Nursing), who was concerned with the need to clarify the nursing role and its relationship to the medical role and that of other disciplines. Legally, 'doctors are responsible for treatment and nurses are responsible for care.' 'Care' is an all-embracing word as defined by Virginia Henderson in her book The Nature of Nursing (1956): 'to assist the individual, sick or well, in the performance of those activities contributing to health or its recovery (or to peaceful death) that he would perform unaided if he had the necessary strength, will or knowledge and to do this in such a way as to help him gain independence as rapidly as possible.'

Mr Bailey outlined the four stages of the nursing process: assessment, planning, implementation and evaluation, but he pointed out that these were not necessarily separate and sequential steps but might take place simultaneously. A central feature of the process was that goals were set and documented, and the extent to which they had been achieved were considered during the patient's hospital stay, on discharge and at follow-up.

The development of such skills required new attitudes on the part of nurses. They must be aware of their own feelings, prejudices and motives and how these could act upon the patient. It was important to observe patients closely and to be aware of non-verbal as well as verbal communication. Interviewing skills had to be developed enabling rapport to be established with the patient, however difficult. This should be extended to other members of the patient's family and nurses had to be aware of the importance of using all available sources of data.

Having arrived at a formulation of the patient's needs and documented the information, the planning and implementation depended upon the smooth functioning of the whole team. It was therefore important to have good lines of communication between team members and for individual members to know what was expected of them.

Evaluation was perhaps the most difficult task and the newest. The other activities described have been part of nursing for many years. Deciding how far the care of the patient was successful, and where and why it had failed was difficult, but essential. The 'nursing process' should provide a theoretical as well as a practical framework for organizing and evaluating the care delivered to the patient.

Mr Alan Stirton (Assistant Director of Nurse Education at the Charles Frears School of Nursing, Leicester) then dealt with the training of psychiatric nurses. He highlighted the difference between medical and nursing training explaining that nurses are hospital employees who are expected to contribute to ward work throughout their course, and that until recently, great emphasis had been laid upon such 'ward work' even in examinations. A move towards a more theoretical approach, in some cases a full degree course and in others to post-basic diplomas in subjects such as psychology, was taking place.

Professor C. P. Seager (Department of Psychiatry, Sheffield University) drew attention in particular to the need for nurses to understand the training of doctors and the relative narrowness of a medical student's experience of the practical side compared with that of nurses before qualification. The house physician or senior house officer was still very much in training because the earlier part of his or her studies had been highly academic and often little attention had been paid to attitudes and skills in dealing with people. These were, of course, fundamental to the good practice of psychiatry, yet young doctors might well lag far behind in the acquisition of these skills.

Professor Seager felt that there should be much more sharing of clinical activities between doctors and nurses and that they should be equal participants in the assessment of patients. Unit administration should be shared as should educational activities.

During the afternoon session, MR P. D. Birchenall (College of Ripon and York St John), DR YORK-MoORE (Lea Castle Hospital, Kidderminster), MR P. Fox (Senior Nursing Officer, Sherwood Hospital, Nottingham) and Miss Teresa Winknson (Nurse Tutor, Maudsley Hospital) dealt respectively with the application of the nursing process to mental handicap, the psychiatry of old age and to child and 
adolescent psychiatry. Mr Birchenall drew on his experience as a nurse in mental handicap to discuss similarities between the nursing process objectives and the taxonomy of educational objectives. Dr York-Moore emphasized that there had been a shift in responsibility and accountability towards the nurse, especially because so much of the work with mentally handicapped people now centred on their life outside hospital with relatives or in sheltered accommodation. The development of community units depended very strongly on the mental handicap team of nurses and social workers. A well designed care delivery scheme was needed.

Mr Fox felt that nurses provided the environment for the elderly mentally infirm in which evaluation of patient needs could take place both outside and inside hospital. The care plan should be individual and include a discharge review for those who had been admitted. Documentation was invaluable when there were queries or complaints from relatives.

Miss Teresa Wilkinson drew attention to the value of using some forms of rating scales in assessment and using these to construct a patient profile and a hierarchy of objectives. Clearly it was not always possible to achieve the ideal, and the team might have to settle for limited goals. The important thing was to decide on what was being aimed for in the short and long term and to make a realistic plan.

The papers were followed by a lively, if perhaps predictable, discussion which centred on the general feeling that much of what had been put forward was already taking place but that the ability to document it would depend on staffing levels.

Professor Altschul pointed out that the need to communicate and therefore to document was even greater if there were staff shortages, but many participants felt that in the highly dependent groups such as the elderly mentally ill, the routine tasks were so time consuming as to make these ideas impractical.

Professor Altschul then invited the speakers to sum up their views, and the meeting ended with the overall impression that although psychiatrists and psychiatric nurses may still be struggling to define their individual philosophies and modes of practice, there is no doubt of their mutual esteem and determination to work together in the most effective way for the benefit of patients.

\section{Examination Results}

\section{Preliminary Test-February 1982}

There were 395 candidates, of whom 196 passed.

Ali Riza Akyildiz; Manzoor Alam; Pen Chye Ang; Shakir Ansari; Ann Elaine Arnold;

Lorenzo Bacelle; Deshal Sanatha Bandara; Sukumar Banerjee; Paul Jan Nigel Barczak; Elizabeth Tovani Barron; Laurence David Bell; Nicholas Roland Best; Allun William Beveridge; Anthony Philip Boardman; Arvind Kumar Bodane; Wagdy Abdalla Botros; Elspeth Anne Bradley; Joan Assumpta Ann Bradley; Jennifer Mary Brockington; Dallas John Brodie; Alison Anne Brown; Ronald Vincent Browne; Anna Clare Bullivant;

Isobel Hamilton Campbell; Timothy George Alexander Cantopher; Joanne Mary Carley; Jane Elizabeth Carruthers; Kizhakkanchalil Peringat Chandran; Sabiha Chaudhry; Marco Chiesa; Fidelis Bere Chikara; Miles Stuart Neville Clapham; Catherine Clulow; James Bernard Connelly; Timothy Henry Corn; David John Cottrell; Maria Cecilia Court; Philip William Cummins; Miriam Geraldine Cussen;

Brenda Davies; Mark Davis; Alan George Deane; Peter Denton White; Karel Wilfried De Pauw; Enda Michael Dooley; David Romney Dossetor; Catherine Jean Downie; Francis James Dunne; Pauline Anne Dunn;

Thomas Paul Elliott; Marie Louise Ellis; Morad Abd El Megid El Shazly; Salah El-Din Rashwan Aboul Fadl;
Angela Mary Feltham; Francis Priyalal Fernando; Srilal Anthony Fernando; Bernard Fleming; David Martin Foreman;

Lakshman Galappathie; Mahadavan Ganesan; Linda Gask; Eric William Gehlhaar; Mohan George; Margaret Mary Gill; Orlando Gonzalez; Guy Manning Goodwin;

Abul Muzaffar Muhhamad Habibur Rahman; Hafez El Saied Hafez Amin; Anthony Stephen Hale; Linda Marion Hall; El Awad Hag Mohamed Hamid; Michele Elizabeth Hampson; Adel Rifaat Younan Hanna; Valerie Hawes; David Thomas Mary Healy; Anne Hobbs; Neil Lindsay Holden;

Linda Morag Holmes; John Leslie Hook; Stephen William Hopker; Carmel Mary Hughes; Valerie Charlotte Hughes; Se Fong Hung; Sharafat Hussain; Deborah Hutchinson; John Broadhurst Hyde;

Mohamed Abdel Alaim Ibrahim; Yan Ming Ip; Vinod Subramaniam Iyer; Ravindra Singh Jaiswal; Deborah Jenkins; Andrew Robert Johns; Jean Frew Johnston; Anthony Graham Jolley; Philip Lewis Alan Joseph;

Carole Ann Kaplan; Somapala Silva Kapugama; Chuda Bahadur Karki; Sheena Elizabeth Mary Kirk; David Michael Kopelman; Saroja Krishnaswamy; Nita Kumar; Kumaraswamy Kumarachandran; George Verghese Kurien; 